\title{
KAJIAN TENTANG JALUR PEDESTRIAN BERDASARKAN ASPEK KENYAMANAN
}

\author{
Jhon Kalvin M Sirait ${ }^{(1)}$, Polin D.R. Naibaho ${ }^{(2)}$, Emmy Ria Aritonang ${ }^{(3)}$ \\ (1) Mahasiswa, Prodi Arsitektur, Fakultas Teknik, Universitas Katolik Santo Thomas Sumatera Utara \\ (2) Staff Pengajar, Prodi Arsitektur, Fakultas Teknik, Universitas Katolik Santo Thomas Sumatera Utara \\ Email: polin.naibaho@ust.ac.id \\ (3) Staff Pengajar, Prodi Arsitektur, Fakultas Teknik, Universitas Katolik Santo Thomas Sumatera Utara \\ Email: emmyria1@gmail.com
}

\begin{abstract}
Pedestrian path is a space for pedestrian activities to carry out activities and to provide services to pedestrians so that it can improve the smoothness, safety, and comfort of pedestrians when crossing it. In fact the pedestrian paths that exist are mostly unable to meet the passions of pedestrians. The length of time pedestrians are less noticed, which should be passed comfortably suddenly blocked by poles, trees, trash cans, stops, and traffic signs because the placement is not adjusted to the place so that the circulation of road users becomes narrow and disturbed. This study aims to find aspects of comfort in the pedestrian path. Research uses quantative methods. This study found that some of the pedestrian path in the study area were comfortable, but some were uncomfortable.
\end{abstract}

Keywords: pedestrian, comfort

\begin{abstract}
Abstrak
Jalur pedestrian adalah ruang untuk kegiatan pejalan kaki melakukan aktivitas dan untuk memberikan pelayanan kepada pejalan kaki sehingga dapat meningkatkan kelancaran, keamanan, dan kenyamanan bagi pejalan kaki pada saat melintasinya.Pada kenyataannya jalur-jalur pedestrian yang ada sebagian besar tidak dapat memenuhi keinginan para pejalan kaki.Lama kelamaan pedestrian kurang begitu diperhatikan, yang seharusnya nyaman dilalui tiba-tiba dihalang tiang, pohon, tempat sampah, halte, dan rambu-rambu lalu lintas dikarenakan perletakannya tidak disesuai pada tempatnya sehingga sirkulasi pengguna jalan menjadi sempit dan terganggu. Penelitian ini bertujuan untuk menemukan aspek kenyamanan pada jalur pedestrian. Penelitian menggunakan metode kuantatif. Penelitian ini menemukan bahwa sebagian jalur pejalan kaki dikawasan kajian sudah nyaman, namun ada juga yang tidak nyaman.
\end{abstract}

Kata-kunci : pedestrian, nyaman

\section{Pendahuluan}

Pedestrian itu sangat penting diadakan karena berfungsi sebagai ruang sirkulasi bagi pejalan kaki yang terpisah dari sirkulasi kendaraan lainnya, baik kendaraan bermotor atau tidak. Setiap orang harus memilki kesadaran tentang betapa pentingnya fungsi jalur pedestrian ini bagi setiap warga sebuah kota. Pedestrian yang jalurnya telah diakomodasi di hampir seluruh wilayah perkotaan mempunyai keinginan yaitu keamanan dan kenyamanan dalam berjalan kaki.

Pedestrian berasal dari bahasa Yunani pedosyang berarti kaki (Oxford Advance Learner's Dictionary of Current English, A.S Hornby (1998)). Dalam bahasa inggris, sebagai kata benda, pedestrian berarti "orang yang berjalan kaki" (Kamus Inggris-Indonesia, John dan Hassan, 1982). Fungsi dari jalur pedestrian ini sangat penting bagi pejalan kaki serta jalur pedestrian ini merupakan salah satu elemen yang berpengaruh di dalam perancanaan tata ruang kota.Faktor lain yang mendorong pejalan kaki memanfaatkan jalur pedestrian untuk berbagai kegiatan statis dan dinamis, antara lain : terdapat ruang 
untuk duduk, perlindungan dari angin, adanya pepohonan, pedagang kaki lima dan tersedianya air, Whyte $(1980 ; 40)$.

\section{Tinjauan Teoritis}

2.1 Jenis-jenis Jalur Pedestrian/Pejalan Kaki

1. Jalur Pedestrian Terlindung

Fasilitas jalur pedestrian yang terlindung didalam bangunan, misalnya :

1. Fasilitas jalur pedestrian arah vertikal, yaitu fasilitas jalur pedestrian yang menghubungkan lantai bawah dan lantai diatasnya dalam bangunan atau gedung bertingkat, seperti tangga, ramps, dan sebagainya.

2. Fasilitas jalur pedestrian arah horizontal, seperti koridor, hall, dan sebagainya.

Fasilitas Jalur Pedestrian yang terlindung di luar bangunan, misalnya:

1. Arcade, yaitu merupakan selasar yang terbentuk oleh sederetan kolom-kolom yang menyangga atap yang berbentuk lengkungan-lengkungan busur dapat merupakan bagian luar dari bangunan atau berdiri sendiri.

2. Gallery, yaitu lorong yang lebar, umumnya terdapat pada lantaiteratas.

3. Covered Walk atau selasar, yaitumerupakan fasilitas pedestrianyang pada umumnya terdapat dirumah sakit atau asrama yangmenghubungkan bagian bangunanyang satu dengan bangunan yanglainnya.

4. Shopping mall, merupakan fasilitas pedestrian yang sangat luas yang terletak di dalam bangunan dimana orang berlalulalang sambil berbelanja langsung di tempat itu.

\section{Jalur pedestrian Tidak Terlindung}

Fasilitas jalur pedestrian yang tidak terlindung / terbuka, yang terdiri dari :

1. Trotoar/sidewalk, yaitu fasilitas jalur pedestrian dengan lantai perkerasan yang terletak di kanan-kiri fasilitas jalan kendaraan bermotor

2. Foot path /jalan setapak, yaitu fasilitas jalur pedestrian seperti ganggang di lingkungan permukiman kampung

3. Plaza, yaitu tempat terbuka dengan lantai perkerasan, berfungsi sebagai pengikat massa bangunan, dapat pula sebagai pengikat-pengikat kegiatan

4. Pedestrian mall, yaitu jalur pedestrian yang cukup luas, disamping digunakan untuk sirkulasi pejalan kaki juga dapat dimanfaatkan untuk kontak komunikasi atau interaksi sosial

5. Zebra cross, yaitu fasilitas jalur pedestrian sebagai fasilitas untuk menyeberang jalan kendaraan bermotor.

\subsection{Jenis dan Kelengkapan Fasilitas Jalur Pedestrian}

Dalam perencanaan fasilitas jalur pedestrian diperlukan pendekatan secara optimal terhadap lokasi dimana jalur pedestrian tersebut berada. Disampingpertimbangan tersebut, yang terpenting dalam perencanaanfasilitas jalur pedestrian adalah mengenai komposisi, warna, bentuk, ukuran serta tekstur.

\section{Fasilitas Utama Jalur Pedestrian}

\section{Trotoar}

Bagiandari daerah manfaat jalan yang berfungsi sebagai jalur pejalan kaki yang pelayanannya ditingkatkan/diperkeras, yang dirancang berdasarkan kebutuhan minimum dengan memperhatikan keamanan, kelancaran dan kenyamanan bagi pejalan kaki dan penyandang cacat.

\section{Penyeberangan pejalan kaki}

\section{a. Zebra Cross}

Salah satu jenis penyeberangan jalan sebidang yang dirancang dengan atau tanpa pelindung yang terletak dipersimpangan tanpa alat pemberi isyarat lalu lintas.

\section{b. Pelican Crossing}

Perangkat peralatan teknis yang menggunakan isyarat lampu, berfungsi untuk mengatur pejalan kaki yang melintas disuatu ruas jalan

c. Jembatan penyeberangan orang 
Digunakan untuk menyeberang pejalan kaki dari satu sisi jalan kesisi jalan yang lainnya.

Elemen-elemen material yang umumnya digunakan pada jalur pedestrian adalah paving (beton), bata atau batu.

\section{- Paving atau beton}

Paving beton dibuat dengan variasi bentuk,tekstur, warna, dan variasi bentuk yangmemiliki kelebihan terlihat seperti batu bata,serta pemasangan dan pemeliharaannyamudah. Paving beton ini dapat digunakan diberbagai tempat karena kekuatannya.

\section{- Batu}

Batu merupakan salah satu material yang paling tahan lama, memiliki daya tahan yang kuat dan mudah dalam pemeliharaannya. Batu granit adalah salah satu yang sering digunakan pada jalur pedestrian yang membutuhkan keindahan.

- Bata

Bahan material ini merupakan bahan yang mudah pemeliharaannya, serta mudah pula didapat. Bata memiliki tekstur dan dapat menyerap air dan panas dengan cepat tetapi mudah retak.

\subsection{Fasilitas Pendukung Jalur Pedestrian}

1. Rambu

Adalah salah satu jenis perlengkapan jalan, berupa lambang, huruf, angka, kalimat, dan atau perpaduan diantaranya sebagai peringatan, larangan, perintah atau petunjuk bagi pejalan kaki.

2. Lampu Penerangan

Memberikan pencahayaan pada malam hari agar area fasilitas pejalan kaki dapat lebih aman dan nyaman. Lampu penerangandiletakkan pada jalur fasilitas terletak setiap 10 meter dengan tinggi maksimal 4 meterdan bahan yang digunakan adalahbahan dengan daya tahan yang tinggi seperti metal dan beton cetak.

3. Pagar Pengaman

Pagar pengaman ditempatkan pada titik tertentu yang berbahaya dan memerlukan perlindungan. Pagar pengaman diletakan dengan tinggi $90 \mathrm{~cm}$.

4. Pelindung/Peneduh

Jenis pelindung/ peneduh disesuaikan dengan fasilitas pejalan kaki dapat berupa: pohon pelindung, atap, dan lain sebagainya. Pelaksanaan teknis pemasangan pelindung/peneduh mengikuti Pedoman Teknik Lansekap Jalan.

5. Tempat Sampah

Tempat sampah diletakan pada jalur fasilitas. Penempatan tempat sampah pada fasilitas pejalankaki hanya untuk menampung sampah yang dihasilkan oleh pejalan kaki.

6. Halte/Tempet pemberhentian bis

Sarana bagi kendaraan penumpang umum, yang berfungsi sebagai tempat pemberhentian umum untuk menurunkan dan menaikkan penumpang.

\section{Drainase}

Drainase terletak berdampingan atau dibawah dari fasilitas pejalan kaki. Drainase berfungsi sebagai penampung dan jalur aliran air pada fasilitas pejalan kaki. Keberadaan dr ainase akan dapat mencegah terjadinya banji dan genangan-genangan air pada saat hujan.

8. Bolar

Pemasangan bolard dimaksudkan agar kendaraan bermotor tidak masuk ke fasilitas pejalankaki sehingga pejalan kaki merasa aman dan nyaman bergerak.

9. Fasilitas Telepon Umum

Telepon umum diletakan pada jalur fasilitas. Terletak pada setiap radius 300 meter atau pada titik potensial kawasan, dengan besaran sesuai kebutuhan dan bahan yang digunakan ada lah bahan yang memiliki daya tahan yang tinggi. 


\section{Tempat Duduk}

Tempat duduk diletakan pada jalur fasilitas. Terletak setiap 10 meter dengan lebar $40-50 \mathrm{~cm}$, panjang $150 \mathrm{~cm}$ dan bahan yang digunakan adalah bahan dengan durabilitas tinggi seperti metal dan beton cetak.

11. Ramp

Suatu jalur yang mempunyai kelandaian tertentu atau mendatar yang terletak pada ruas/jalan yang direncanakan untuk pejalan kaki dan penyandang cacat yang pelayanannya dipertimbangkan sehingga bisa dipakai sesuai dengan fungsinya masing-masing.

\subsection{Faktor-faktor Yang Mempengaruhi Kenyamanan}

Kenyamanan merupakan segala sesuatu yang memperlihatkan dirinya sesuai dan harmonis denganpenggunaan suatu ruang. Jalur pedestrian memiliki peran penting dalam pembentukan arsitektur kota. Kondisi jalur pedestrian yang mengutamakan kenyamanan, tentunya juga mempertimbangkan aspek manusiawi.

Menurut Rustam Hakimdan Hardi Utomo (2003 : 185) kenyamanan adalah segala sesuatu yang memperlihatkan penggunaan ruang secara sesuai dan harmonis, baik dengan ruang itu sendiri maupun dengan berbagai bentuk, tekstur, warna, simbol mapun tanda, suara dan bunyi kesan, intensitas dan warna cahaya ataupun bau, atau lainnya. Kenyamanan dapat pula dikatakan sebagai kenikmatan atau kepuasan manusia dalam melaksanakan kegiatannya.

Hakim dan Utomo (2003 : 186) mengemukakan bahwa faktor-faktor yang mempengaruhi kenyamanan antara lain :

\section{Sirkulasi}

Kenyamanan suatu ruang dapat berkurang akibat sirkulasi yangtidak tertata dengan benar, misalnya kurang adanya kejelasan sirkulasi, tiadanya hierarki sirkulasi, tidak jelasnya pembagian ruang dan fungsi ruang, antara sirkulasi pejalan kaki (pedestrian) dengan sirkulasi kendaraan bermotor (Hakim dan Utomo, 2003 : 186).

Untukterciptanya kelancaran masing-masing aktifitas sirkulasi, maka sirkulasi bebas dari penghalang yang mengganggu pengguna jalan.

\section{Iklim atau Kekuatan Alam}

Faktor iklim adalah faktor kendala yang harus mendapat perhatian serius dalam merekayasa sistem jalan yang terkonsep.Salah satu kendala iklim yang muncul adalah curah hujan, faktor ini tidak jarang menimbulkan gangguan terhadap aktifitas para pejalan kaki, terutama di musim penghujan. Oleh karena itu perlu disediakan tempat berteduh apabila terjadi hujan, seperti shelter dan gazebo.

\section{Kebisingan}

Tingginya tingkat kebisingan suara kendaraan bermotoryang lalu lalang, juga menjadi masalah vital yang dapat mengganggu kenyamanan bagi lingkungan sekitar dan pengguna jalan, terutama pejalan kaki. Oleh sebab itu untuk meminimalisir tingkat kebisingan yang terjadi, dapat dipakai tanaman dengan pola dan ketebalan yang rapat serta tersusun teratur. Namun kebisingan yang muncul dari faktor-faktor lain (sepertitransaksi perdagangan dari PKL, kebisingan parkir liar, dan sebagainya).

\section{Aroma atau bau-bauan}

Aroma atau bau-bauan yang tidak sedap berasal dari sampah. Selain itu, kadang terdapat areal pembuangan sampah yang tidak jauh dari daerah perlintasan jalan, maka bau yang tidak menyenangkan akan tercium oleh para pengguna jalan, baik yang berjalan kaki maupun para pemakai kendaraan bermotor. Untuk mengurangi gangguan aroma yang kurang sedap tersebut, maka trotoar bisa diberikan sekat penutup tertentu sebagai pandangan visual serta dihalangi oleh tanaman, pepohonan yang cukup tinggi, maupun dengan peninggian muka tanah. 


\section{Bentuk}

Bentuk elemen landscape furniture harus disesuaikandengan ukuran standar manusia agar skala yang dibentuk mempunyai rasa nyaman (Hakim dan Utomo, 2003 : 190). Sebagai contoh, jalur pedestrian dan jalur kendaraan memiliki ketinggian berbeda dan mempunyai pembatas yang jelas (kereb). Bentuk yang semacam itu akan mengakibatkan, jalur trotoar menjadi aman dari kendaraan bermotor.

\section{Keamanan}

Tanudjaja dalam Pamungkas (2003 : 19) menyatakanbahwa manusia memiliki jenjang kebutuhan, yang salah satunya adalah safety need. Safety need merupakan kebutuhan manusia yang berkaitan dengan keselamatan atau keamanan, supaya dirinya merasa terlindungi dari setiap gangguan. Misalnya peletakan furnitute harus sesuai dengan tempatnya, supaya jalur pejalan kaki bebas dari hambatan.

\section{Kebersihan}

Daerah yang terjaga kebersihannya akan menambah dayatarik khusus, selain menciptakan rasa nyaman serta menyenangkan orang-orang yang melalui jalur trotoar. Untuk memenuhi kebersihan suatu lingkungan perlu disediakan bak-bak sampah sebagai elemen lansekap dan sistem saluran air selokan yang terkonsep baik.

\section{Keindahan}

Keindahan suatu ruang perlu diperhatikan secara seriusuntuk memperoleh suasana kenyamanan. Keindahan harus selalu terkontrol penataannya, memperhatikan dari berbagai bentuk, warna komposisi susunan tanaman dan elemen perkerasan. Keindahan mencakup persoalan kepuasan bathin dan panca indera manusia.

Permasalahan dalam penelitian ini adalah Bagaimana kenyamanan pada jalur pedestrian dijalan Putri Hijau perpotongan dengan jalan Guru Patimpus-jalan Perintis Kemerdekaan Medan di tinjau berdasarkan aspek kenyamanan dan Bagaimanakah fasilitas pendukung yang ada bila dikaitkan atribut kenyamanan. Adapun tujuan dalam penelitian ini adalah Menemukan aspek kenyamanan pada jalur pedestrian di jalan Putri Hijau perpotongan dengan jalan Guru Patimpus-jalan Perintis Kemerdekaan Medan dan Mengetahui fasilitas pendukung yang ada bila dikaitkan dengan standart-standart kenyamanan.

\section{Metode}

Jenis penelitian yang dilakukan adalah Penelitian Deskriptif-Kualitatif. Jenis penelitian ini bertujuan untuk memberikan penggambaran secara mendalam tentang situasi atau proses yang diteliti, mengumpulkan dan menggunakan data yang berupa narasi cerita, penuturan informaln, dokumendokumen pribadi seperti poto, catatan pribadi,perilaku, gerak tubuh, dan mimik.Penelitian dalam Seminar ini akan mengkaji tentang jalur pedestrian ditinjau berdasarkan aspek kenyamanan yang berada dijalan Putri Hijau perpotongan dengan jalan Guru Patimpus-jalan Perintis Kemerdekaan Medan dan membandingkannya dengan studi litelatur yang berkaitan dengan pedestrian berdasarkan aspek kenyamanan.

\subsection{Metode Pengumpulan Data}

Data penelitian terdiri dari data primer dan data sekunder.

\section{Data Primer}

Adalah data yang diperoleh atau dikumpulkan oleh peneliti secara langsung dari sumber datanya. Data Primer disebut juga sebagai data asli atau data baru yang memiliki sifat up to date.Untuk mendapatkan data primer, peneliti harus mengumpulkan secara langsung.Teknik yang digunakan untuk mengumpulkan data primer adalah :

a. Pengamatan (Observasi)

Teknik pengumpulan data yang dilaksanakan dengan cara pengamatan secara langsung kesasaran penelitian agar didapat data yang benar-benar sesuai yang diinginkan. 
b. Memetaan lokasi

Teknik pengambilan data dengan cara mengsketsakan denah mapping serta elemen-elemen yang ada pada jalur pedestrian.

\section{Data Sekunder}

Adalah data yang diperoleh atau dikumpulkan peneliti dari berbagai sumber yang telah ada (peneliti sebagai tangan kedua). Data sekunder dalam penelitian ini diperoleh dari berbagai sumber seperti Departemen Pekerjaan umum tentang Tata cara Perencanaan Fasilitas Pejalan Kaki Dikawasan Perkotaan, Buku Pedestrian Ways dalam Perancangan Kota, laporan, jurnal, dan lain-lain, baik media cetak maupun media elektronikJelaskan metode pengumpulan data yang digunakan, misalnya survei, observasi atau arsip, disertai rincian penggunaan metode tersebut. Bila dianggap perlu, pada bagian ini juga dapat dijelaskan populasi, sampel dan metode pemilihan sampel.

\subsection{Metode Analisis Data}

Kegiatan pengolahan data merupakan suatu data yang diperoleh secara deskripsi kualitatif, yaitu terhadap aspek pelaku kegiatan dijalur pedestrian. Kemudian dianalisis secara kuantatif dari seluruh fungsi kegiatan di jalur pedestrian. Kemudian dimasukkkan dalam skala pengukuran untuk menentukan bobot penilaian dari fungsi jalur pedestrian supaya dapat ditarik kesimpulan dan saran dari hasil analisis tersebut.

\section{Skala Penilaian}

Skala penilaian (Rating Scale) adalah cara pengumpulkan data yang digunakan dalam observasi untuk menjelaskan, menggolongkan, menilai individu atau situasi. Dalam penelitian ini, menggunakan skala penilaian Grafik(Graphic Rating Scales).Dimana peneliti diminta untuk mencek titik tertentu dari suatu kontinum pada suatu garis tertentu. Dalam menentukan Skor, peneliti menggunakan jenjang (range) 3 (1,2,3).Dengan adanya skor, pembobotan penilaian bisa dilakukan.

Keterangan sebagai berikut :

1 = Sangat tidak baik/sangat rendah/tidak pernah

2 = Kurang baik/cukup/kadang-kadang

3 = Sangat baik/sangat tinggi/selalu

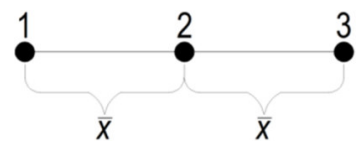

Dan untuk membuat nilai rata-rata atau Mean menggunakan rumus umum :

$$
\bar{x}=\frac{x_{1}+x_{2}+\ldots+x_{n}}{n}
$$

Keterangan sebagai berikut :

$\bar{x}=$ rata-rata hitung

$x_{i}=$ nilai sampel ke-i

$n=$ jumlah sampel

\section{Kriteria Penilaian}

Dalam penelitian ini, kriteria penilaian yang akan digunakan berdasarkan dari yang dikemukan oleh Hakim dan Utomo (2003 : 186), yaitu faktor-faktor yang mempengaruhi kenyamanan bagi pejalan kaki. 
Tabel 1. Tabulasi Kriteria penilaian jalur pedestrian yang mempengaruhi kenyamanan

\begin{tabular}{|c|c|c|c|c|}
\hline No & Aspek Keny & yamanan & Kriteria Analisis & Nilai \\
\hline \multirow[t]{4}{*}{1} & \multirow[t]{4}{*}{ Sirkulasi } & \multirow{4}{*}{$\begin{array}{l}\text { - Lebar pedestrian minimal } 165 \mathrm{~cm} \\
\text { untuk jalan } 2 \text { orang bebas dari } \\
\text { penghalang dan jalur pedestrian tidak } \\
\text { licin dan bertekstur }\end{array}$} & Selalu bersinggungan (sempit) & \\
\hline & & & jarak $120 \mathrm{~cm}$ & 1 \\
\hline & & & $\begin{array}{l}\text { Sesekali bersinggungan dan harus } \\
\text { ada yang mengalah } \\
\text { Jarak } 140 \mathrm{~cm}\end{array}$ & 2 \\
\hline & & & $\begin{array}{l}\text { Tidak bersinggungan dan sirkulasi } \\
\text { lancar, tidak licin }\end{array}$ & 3 \\
\hline \multirow[t]{3}{*}{2} & \multirow{3}{*}{$\begin{array}{l}\text { Iklim atau } \\
\text { kekuatan } \\
\text { alam }\end{array}$} & \multirow{3}{*}{$\begin{array}{l}\text { - Penanaman pohon sebagai peneduh } \\
\text { dari sinar matahari } \\
\text { - Pembuatan shalter, gazebo tempat } \\
\text { berteduh dari cuaca (panas atau } \\
\text { hujan) }\end{array}$} & Tidak mempunyai peneduh & 1 \\
\hline & & & $\begin{array}{l}\text { Terdapat pohon sebagai peneduh } \\
\text { dan sebagian tidak }\end{array}$ & 2 \\
\hline & & & $\begin{array}{l}\text { Terdapat pohon peneduh dan } \\
\text { terdapat halte }\end{array}$ & 3 \\
\hline \multirow[t]{3}{*}{3} & \multirow[t]{3}{*}{ Kebisingan } & \multirow{3}{*}{$\begin{array}{l}\text { - Menggunakan tanaman dengan pola } \\
\text { dan rapat tersusun teratur untuk } \\
\text { mengurangi kebisingan/menantulkan }\end{array}$} & Tidak ada vegetasi & 1 \\
\hline & & & $\begin{array}{l}\text { Terdapat vegetasi sebagai } \\
\text { pembatas dan sebagian tidak }\end{array}$ & 2 \\
\hline & & & $\begin{array}{l}\text { Terdapat vegetasi dengan } \\
\text { berdaun padat }\end{array}$ & 3 \\
\hline \multirow[t]{4}{*}{4} & \multirow[t]{4}{*}{$\begin{array}{l}\text { Aroma atau } \\
\text { bau-bauan }\end{array}$} & \multirow{4}{*}{$\begin{array}{l}\text { - Trotoar harus diberi penutup } \\
\text { - Material penutup pada jaringan } \\
\text { drainase harus selalu terpelihara } \\
\text { kebersihannya }\end{array}$} & $\begin{array}{l}\text { Tidak adanya penutup pada } \\
\text { trotoar }\end{array}$ & 1 \\
\hline & & & Adanya penutup, tetapi berlubang & 2 \\
\hline & & & Tertutup dan kondisi baik & \\
\hline & & & & 3 \\
\hline \multirow[t]{3}{*}{5} & \multirow[t]{3}{*}{ Bentuk } & \multirow{3}{*}{$\begin{array}{l}\text { - Bentuk jalur pejalan kaki jelas ditemui } \\
\text { karena adanya perbedaan tinggi } \\
\text { dengan jalur kendaraan minimal 26-38 } \\
\text { cm } \\
\text { - Tepi jalur harus kuat }\end{array}$} & $\begin{array}{l}\text { Sejajar dengan jalan, ketinggian < } \\
25 \mathrm{~cm}\end{array}$ & 1 \\
\hline & & & Ketinggian mendekati $26 \mathrm{~cm}$ & $\frac{1}{2}$ \\
\hline & & & $\begin{array}{l}\text { Ketinggian }=26 \quad \mathrm{~cm}, \quad \text { jelas } \\
\text { perbedaan antara pedestrian dan } \\
\text { jalur kendaraan }\end{array}$ & 3 \\
\hline \multirow[t]{3}{*}{6} & \multirow[t]{3}{*}{ Keamanan } & \multirow{3}{*}{$\begin{array}{l}\text { - Perletakan furniture disusun dengan } \\
\text { teratur sesuai dengan tempatnya tanp } \\
\text { menghalangi sirkulasi } \\
\text { - Pagar pengaman sebagai } \\
\text { pembatas }\end{array}$} & $\begin{array}{l}\text { Furniture sebagian hilang, tidak } \\
\text { adanya pengaman jalan }\end{array}$ & 1 \\
\hline & & & $\begin{array}{l}\text { Furniture ada tetapi peletakannya } \\
\text { tidak sesuai tempatnya }\end{array}$ & 2 \\
\hline & & & $\begin{array}{l}\text { Kelengkapan furniture, dan Pagar } \\
\text { pengaman sebagai pembatas } \\
\text { masih baik }\end{array}$ & 3 \\
\hline \multirow[t]{3}{*}{7} & \multirow[t]{3}{*}{ Kebersihan } & \multirow{3}{*}{$\begin{array}{l}\text { - Jarak antara tempat sampah 15-20 } \\
\text { meter } \\
\text { - Disediakan tempat sampah kering dan } \\
\text { tampat sampah basah }\end{array}$} & Tidak adanya tempat sampah & 1 \\
\hline & & & $\begin{array}{l}\text { Adanya tempat sampah dengan } \\
\text { jarak berdekatan }\end{array}$ & 2 \\
\hline & & & $\begin{array}{l}\text { Tempat sampah dengan standart } \\
\text { jarak } 15-20 \mathrm{~m} \text {, Tempat sampah } \\
\text { kering dan tempat sampah basah }\end{array}$ & 3 \\
\hline \multirow[t]{4}{*}{8} & \multirow[t]{4}{*}{ Keindahan } & \multirow{4}{*}{$\begin{array}{l}\text { - Memperhatikan dari berbagai segi } \\
\text { bentuk, warna komposisi susunan } \\
\text { tanaman dan elemen perkerasan. }\end{array}$} & $\begin{array}{l}\text { Komposisi warna yang membuat } \\
\text { keliru }\end{array}$ & 1 \\
\hline & & & Terdapat bingkai visual yang baik & \\
\hline & & & & 2 \\
\hline & & & Terdapat bingkai visual yang baik & \\
\hline
\end{tabular}


Keterangan :

1 = Tidak Baik

2 = Cukup Baik

3 = Sangat baik

\section{Hasil Analisis dan Interpretasi}

Berikut adalah analisa dari penelitian:

Tabel 2. Hasil Kesimpulan Analisis Kasus Segmen Sisi Kiri

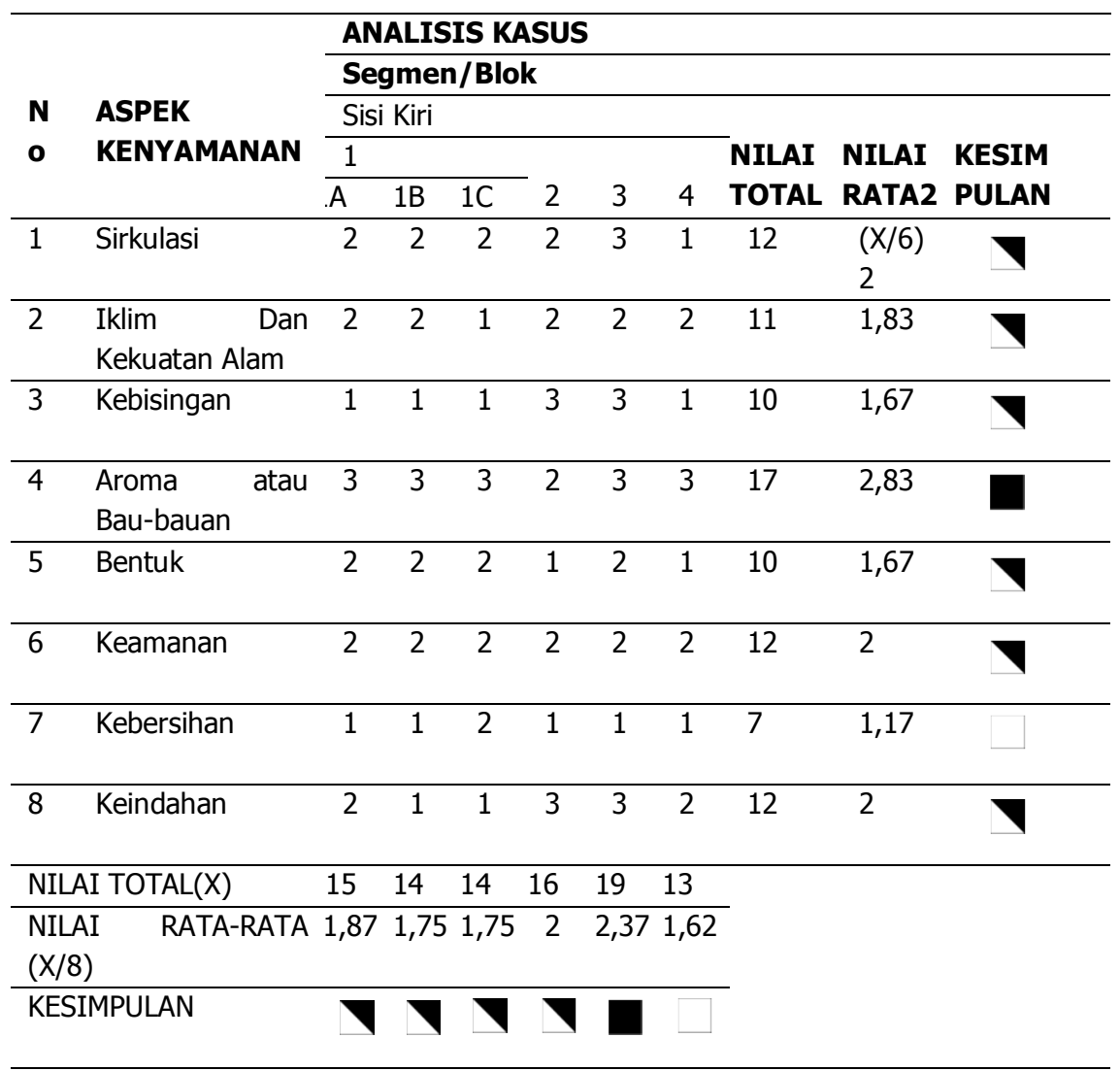

Tabel 3. Hasil Kesimpulan Analisis Kasus Segmen Sisi Kanan

\begin{tabular}{|c|c|c|c|c|c|c|c|c|}
\hline \multirow{5}{*}{ No } & \multirow{5}{*}{$\begin{array}{l}\text { ASPEK } \\
\text { KENYAMANAN }\end{array}$} & \multicolumn{7}{|c|}{ ANALISIS KASUS } \\
\hline & & \multicolumn{7}{|c|}{ Segmen/Blok } \\
\hline & & \multicolumn{4}{|c|}{ Sisi Kanan } & \multirow[b]{2}{*}{ NILAI } & \multirow{3}{*}{$\begin{array}{l}\text { NILAI } \\
\text { RATA2 }\end{array}$} & \multirow{3}{*}{$\begin{array}{l}\text { KESIM } \\
\text { PULAN }\end{array}$} \\
\hline & & & & & & & & \\
\hline & & 5 & 6 & 7 & 8 & TOTAL & & \\
\hline \multirow[t]{2}{*}{1} & Sirkulasi & 1 & 1 & 2 & 2 & 6 & $(X / 4)$ & \\
\hline & & & & & & & 1,5 & \\
\hline \multirow[t]{2}{*}{2} & Iklim Dan & 2 & 2 & 2 & 2 & 8 & 2 & \\
\hline & Kekuatan Alam & & & & & & & \\
\hline 3 & Kebisingan & 3 & 3 & 3 & 3 & 12 & 3 & \\
\hline
\end{tabular}




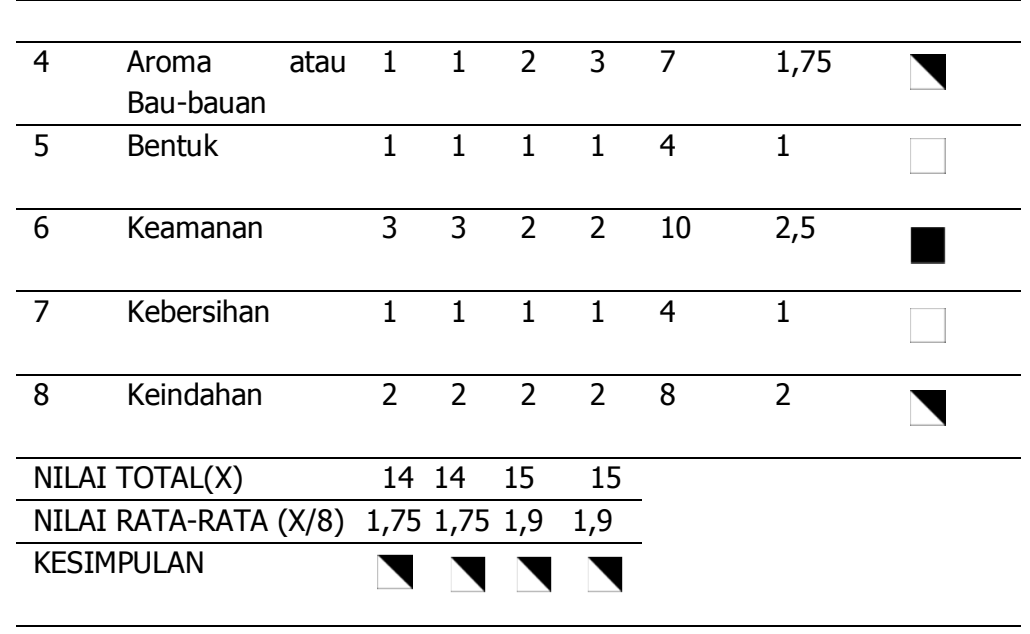

Keterangan bobot nilai rata-rata :

$$
\begin{aligned}
\square 1,00-1,66= & \text { Tidak memiliki } \\
& \text { kenyamanan } \\
1,67-2,26= & \text { Cukup memiliki } \\
& \text { kenyamanan } \\
2,27-3,00= & \text { Sangat memiliki } \\
& \text { Kenyamanan }
\end{aligned}
$$

Untuk menentukan nilai rata-rata tiap segmen, adalah sebagai berikut :

$$
\text { Nilai }(1+2+3+4+5+6+7+8)=X
$$

\section{NILAI RATA-RATA $(X / 8)$}

Untuk menentukan nilai rata-rata tiap kriteria, penilaiannya dibagi menjadi 2 sisi, adalah sebagai berikut :

Sisi kiri : $\quad$ Nilai $(1 A+1 B+1 C+2+3+4)=X$

NILAI RATA-RATA $(X / 6)$

Sisi kanan : $\quad$ Nilai $(1+2+3+4)=X$

\section{NILAI RATA-RATA (X/4)}

\section{Kesimpulan}

Dari Studi jalur pedestrian di jalan Putri Hijau Medan yang terdiri dari 8 segmen didapatkan kesimpulan :

1. Segmen 1A, didepan Hotel Inna Dharma Deli, memiliki nilai $\mathbf{1 , 8 7}$ (Cukup memiliki kenyamanan). Dengan lebar sirkulasi sudah memenuhi standart. Menggunakan bahan cor beton bertekstur dan tidak licin. Tetapi peletakan papan iklan, pot bunga, signage dan pohon tidak sesuai dengan tempatnya, sehingga jalur pedestrian terasa tidak nyaman dan sempit. Peletakan JPO juga memakan jalur pedestrian. Tepi pemisah jalur pejalan kaki dengan jalur kendaraan mendekati standart, tidak ada pagar pengaman, kebersihannya kurang karena tidak terdapat tempat sampah. Dan terdapat bingkai visual berupa pagar dinding dengan tinggi $40 \mathrm{~cm}$.

2. Segmen 1B, didepan Showroom Toyota, memiliki nilai $\mathbf{1 , 7 5}$ (Cukup memiliki kenyamanan). Lebar sirkulasi sudah memenuhi standart. Menggunakan bahan cor beton bertekstur dan tidak licin. Pot bunga, Halte, PKL, berada ditengah jalur pedestrian, sehingga pengguna jalan harus turun 
menggunakan jalur kendaraan. Tidak ada vegetasi berdaun lebat. Trotoar tertutup dibawa jalur pedestrian. Tidak terdapat tempat sampah dan pagar pengaman. Tidak ada bingkai visual.

3. Segmen 1C, didepan gedung Komersil (Pusat Perbelanjaan), memiliki nilai 1,75(Cukup memiliki kenyamanan). Lebar sirkulasi sudah memenuhi standart. Menggunakan bahan cor beton bertekstur dan tidak licin. Pot bunga, pohon, tempat sampah, peletakannya tidak sesuai dengan tempatnya. Sehingga jalur pedestrian menjadi sempit. Tidak ada vegetasi berdaun lebat. Trotoar tertutup dibawa jalur pedestrian. Terdapat tempat sampah. Tidak ada bingkai visual dan pagar pengamanan.

4. Segmen 2, didepan gedung Plasa Telkomsel memiliki nilai 2,00(Cukup memiliki kenyamanan). Lebar sirkulasi sudah memenuhi standart. Con blok sebagian rusak dan cor beton banyak yang retak. Terdapat pohon peneduh dari sinar matahari. Trotoar sebagian tanpa penutup. Tepi jalur pedestrian dengan jalur kendaraan terlalu rendah $20 \mathrm{~cm}$. Tidak terdapat tempat sampah. Terdapat bingkai visual berupa pagar dengan tanaman.

5. Segmen 3, didepan gedung Capital Building memiliki nilai $\mathbf{2 , 3 7}$ (Sangat memiliki kenyamanan). Lebar sirkulasi sudah memenuhi standart. Sirkulasi pejalan kaki aman dan nyaman. Kondisi con blok baik. Terdapat pohon peneduh dari sinar matahari. Trotoar tertutup dibawa jalur pedestrian.Peletakan pohon dan tiang listrik sesuai dengan tempatnya. Tepi pemisah jalur pedestrian dengan jalur kendaraan mendekati standart $25 \mathrm{~cm}$. Tidak terdapat tempat sampah.

6. Segmen 4, didepan rencana gedung Podomoro City memiliki nilai $\mathbf{1 , 6 2 ( T i d a k ~ m e m i l i k i ~ k e n y a m a n a n ) . ~}$ Lebar sirkulasi dibawa standart. Kondisi con blok tertimbun dan tergenang air .Peletakan pot bunga dan tiang listrik mengganggu sirkulasi pengguna jalan. Tidak ada pohon berdaun lebat. Tepi pemisah jalur pedestrian dengan jalur kendaraan terlalu rendah $23 \mathrm{~cm}$. Tidak ada tempat sampah dan bingkai visual.

7. Segmen 5, didepangedung komersil memiliki nilai 1,75(Cukup memiliki kenyamanan). Lebar sirkulasi dibawa standart. Kondisi con blok rusak parah. Peletakan pot bunga, pohon, dan tiang listrik sesuai dengan tempatnya. Terdapat pohon peneduh berdaun lebat. Tepi pemisah jalur pedestrian dengan jalur kendaraan terlalu rendah $20 \mathrm{~cm}$. saluran/ parit tanpa penutup dan tidak ada pembatas antara parit dengan con blok. Tidak ada tempat sampah dan bingkai visual.

8. Segmen 6, didepan Kantor Dinas Perindustrian dan perdagangan dan Kantor Wilayah Sumatera Utara memiliki nilai 1,75(Cukup memiliki kenyamanan). Lebar sirkulasi sudah memenuhi standart. Kondisi con blok banyak rusak parah dan banyak yang hilang. Peletakan pot bunga, pohon, dan tiang listrik sesuai dengan tempatnya. Terdapat pohon peneduh berdaun lebat. Tepi pemisah jalur pedestrian dengan jalur kendaraan terlalu rendah $20 \mathrm{~cm}$. saluran/ parit tanpa penutup dan tidak ada pembatas antara parit dengan con blok. Tidak ada tempat sampah dan bingkai visual.

9. Segmen 7, didepan gedung Bank Danamond sampai Bank BRI memiliki nilai 1,90(Cukup memiliki kenyamanan). Lebar sirkulasi dibawa standart. Kondisi con blok banyak rusak (dpn bank Danamond) dan kondisi baik (dpn bank BRI). Terdapat pohon peneduh. Saluran/parit tanpa penutup sehingga mengeluarkan aroma bau tak sedap. Saluran tertutup dengan beton cetak di depan bank BRI. Tepi pemisah jalur pedestrian dengan jalur kendaraan terlalu rendah $20 \mathrm{~cm}$. Perletakan papan iklan terlalu rendah. Terdapat pagar pengaman dpn Bank BRI. Tidak terdapat tempat sampah. Terdapat bingkai visual berupa pagar dinding dengan tanaman (dpn bank BRI).

10.Segmen 8, didepan gedung Komersil memiliki nilai 2,00(Cukup memiliki kenyamanan). Lebar sirkulasi memenuhi standart.Kondisi cor beton masih baik.Terdapat pohon peneduh.Saluran tertutup dibawa jalur pejalan kaki. Tepi pemisah jalur pedestrian dengan jalur kendaraan terlalu rendah $20 \mathrm{~cm}$. Terdapat bingkai visual berupa taman kecil. Peletakan papan iklan terlalu rendah sehingga mengganggu pandangan. Tidak terdapat tempat sampah.

\section{Saran}

Dari hasil penelitian kenyamanan pedestrian di jalan Putri Hijau diperoleh bahwa :

$\checkmark$ Dari segi kenyamanan perlu diperhatikan dan di tingkatkan di semua segmen

$\checkmark$ Dari segi keamanan, jalur pejalan kaki harus dibedakan ketinggiannya dengan jalur kendaraan. Salah satu cara untuk mengatasi hal ini adalah dengan membuat pagar pembatas antara jalur pejalan kaki dengan jalur kendaraan, sehingga ada pembatas yang jelas. 
$\checkmark$ Perlu ditambah fasilitas pendukung disemua segmen dan penempatannya harus diperhatikan

$\checkmark$ Dari semua segmen jalur pedestrian tidak boleh licin

$\checkmark$ Untuk segmen $5,6,7$, saluran parit harus diberi penutup supaya tidak mengeluarkan aroma tidak sedap.

\section{Daftar Pustaka}

Anggriani, Niniek.2009. Pedestrian Ways Dalam Perancangan Kota,Yayasan Humaniora,Klaten.

Departemen Pekerjaan Umum.1999.Tentang Persyaratan Aksesibilitas Pada Jalan Umum,PT.Mediatama Saptakarya,Jakarta.

Mirsa, Rinaldi.2012. Elemen Tata RuangKota,Graha Ilmu,Yogyakarta.

Moh. Nazir, Ph.D.1988. Metode Penelitian,Ghalia Indonesia,Jakarta.

Prof. Dr. Ir. Usman Rianse, MS.2012. Metodologi Penelitian Sosial danEkonimi,Alfabeta,Bandung.

Shirvani, Hamid.1985. The Urban Design Process,Van Nostrand Reinhold Company,New York.

Terstiervy indra pawaka listianto, st tentang Hubungan Hungsi dan KenyamananJalur Pedestrian,2006. 